University of Nebraska - Lincoln

DigitalCommons@University of Nebraska - Lincoln

Faculty Publications, UNL Libraries

Libraries at University of Nebraska-Lincoln

2012

The Value of Partnerships: Building New Partnerships for Success

Joan Giesecke

University of Nebraska-Lincoln, jgiesecke1@unl.edu

Follow this and additional works at: https://digitalcommons.unl.edu/libraryscience

Giesecke, Joan, "The Value of Partnerships: Building New Partnerships for Success" (2012). Faculty Publications, UNL Libraries. 294.

https://digitalcommons.unl.edu/libraryscience/294

This Article is brought to you for free and open access by the Libraries at University of Nebraska-Lincoln at DigitalCommons@University of Nebraska - Lincoln. It has been accepted for inclusion in Faculty Publications, UNL Libraries by an authorized administrator of DigitalCommons@University of Nebraska - Lincoln. 


\title{
The Value of Partnerships: Building New Partnerships for Success
}

\author{
Joan Giesecke \\ University of Nebraska-Lincoln, Lincoln, NE, USA
}

\begin{abstract}
In today's economy, higher education institutions are struggling to maintain quality while functioning with fewer resources. For libraries, the economic situation is compounded by the impact of an information marketplace that is characterized by prices for resources that increase at 7 to $10 \%$ per year, and by near and actual monopolies controlling content. Added to the complexities of the marketplace are the demands of a faculty and student body that prefer individual actions to group efforts. These economic and social issues can become real barriers to innovation, quality improvement, and successful services for today's libraries. One way to combat the economic and social environment is by creating new and improved partnerships to leverage resources and share expertise in order to provide better services and access to wider collections. But forming partnerships is not easy. This paper will review the characteristics of successful partnership as developed by the Gallup Corporation and will show how these values can be used in the academic library environment to create opportunities for success.
\end{abstract}

Keywords: partnerships, collaboration, libraries

\section{Introduction}

In management theory, organizations surviving in times of change move from an emphasis on economy, to efficiency, and then to effectiveness. These organizations realize that they must not only make the best use of their resources (economy), and demonstrate excellence in how tasks are accomplished (efficiency), but must be sure they are doing the right things and are being effective. Along these same lines, man- 
agement theorists have urged organizations to move from bureaucratic models with well defined rules and policies that emphasize efficiency to more participatory models that emphasize shared visions, shared power, and consensus decision-making. Organizations seek to engage their staffs in assessment, evidence-based decisionmaking, and learning organization efforts. They seek to spread responsibility and accountability throughout the organization to improve work processes and services. These efforts have helped organizations develop more flexible processes and to make adjustments as the economic landscape has changed.

Organizations have also sought ways to work together to achieve their goals. Organizations may coordinate efforts, may cooperate on projects, or may turn to collaborations for joint endeavors. Finally, organizations that want to thrive are learning to create partnerships to move the organization forward. Each of these options present different opportunities and challenges for today's organizations.

\section{Coordination}

Coordination of efforts is one of the simplest forms of joint activities. Here, units or organizations try to harmonize actions. Organizations may exchange ideas, alternate activities, or provide access to services and products. The model emphasizes efficiency in working together with a minimal amount of involvement by participants. Often, cooperative efforts are headed by one or two coordinators in communication with others. In coordinated efforts, then, the organizations retain their independence (Montiel-Overall, 2005).

\section{Cooperation}

Cooperative efforts involve more interaction among the members of the organizations than is required by coordination. The organizations involved in cooperative efforts develop norms for working together to achieve a joint or common purpose. The organizations come together willingly for a common good, but still retain their own independence. Cooperative efforts require more trust on the part of participants than simple coordination. There needs to be more understanding of each organization's functions and mandates and a willingness to negotiate to create joint projects. In cooperative efforts, organizations form relationships to come together to share resources such as space, funds, or time. Cooperative efforts are most likely to be successful when the two partners or entities share excellence, recognize the interdependence of the efforts, share investments and information, and build on integrity to develop trust. Joint goal setting, teamwork, and networking are all part of cooperative efforts (Montiel-Overall, 2005). For libraries, many of our consortia arrangements are based on models of cooperation where libraries have formal agreements 
to work together on selected projects while retaining their independence and autonomy in other areas of their organizations work.

\section{When to Form a Partnership}

Not all activities for organizational interactions require or benefit from forming partnerships. At times it is more appropriate for an organization to center activities within the organization or to engage in a more standard market approach for purchasing needed services. This is the classic "make or buy" decision that organizations regularly face. When an activity involves uncertainty and requires frequent investments of time or money that cannot be easily transferred to other functions, it may be best to leave the activity within the organization. For example, colleges are unlikely to contract out academic advising activities as each of these transactions has unique characteristics based on the needs of the student and the options available to them in terms of scheduling, degree criteria, etc. However, when the activity is reasonably straightforward and is cost-effective, the organization may do well to contract with others to provide the service or activity. For example, moving to shelfready purchasing of monographs is a market transaction that is well established in the library field. On the other hand, partnerships are more complex relationships formed around difficult but solvable problems that require creative thinking, sharing of expertise, and where the partners have sufficient capacity to bring resources to the endeavor (Davies \& Hentschke, 2006).

\section{Collaboration and Partnerships-The 21st Century}

In the 21st century, organizations are finding that models of coordination and cooperation are not enough to bring about true change. Organizations need different models of operating in order to thrive in tough times, and to recognize when some services or activities need to be dropped in order to meet the new needs of the customer or patron. Models of partnerships and collaborations can help today's organizations shift their viewpoints to find new ways of working and providing services.

One immediate challenge for organizations that want to embrace more partnership efforts is that there are few agreed to definitions of collaborations, the foundation for partnerships. Most western management philosophy has not addressed the challenges of partnership development. Plato and Aristotle do not address collaboration. Adam Smith talked of division of labor, not joint efforts. Even Karl Marx emphasized the individual (Schrage, 1990, p. 44).

The management theorists of the early zoth century, such as Frederick W. Taylor, also emphasized individual efforts through scientific management, enforced standardization of methods, and enforced adoption of best practices (Scharage, 1990, 
p. 55). The human relations school of management encouraged participation in the organization but did not necessarily develop processes for improving innovation or creativity. Later management theorists continued to emphasize communication and coordinated action rather than shared creation and collaboration. They talk of team work and use sports metaphors to describe organizational behaviors, but fail to note that in sports there are team leaders and followers or team members rather than partners. Each person has a role and a task to perform and needs to fit into the structure. Slowly, theorists have begun to shift their emphasis from individual efforts to group work and from independence to community.

Collaboration includes numerous attributes including partnerships, interactions among co-equals, information sharing and shared vision, joint negotiation of common ground, shared power, joint planning, complementary skills, strategic alliances, creating new values, and multi-organization processes (Montiel-Overall, 2005). Michael Schrage (1990), in Shared Minds, defines collaboration as follows:

Collaboration is the process of shared creation: two or more individuals with complementary skills interacting to create a shared understanding that none had previously possessed or could have come to on their own. Collaboration creates a shared meaning about a process, a product or an effect..... The true medium of collaboration is other people. Real innovation comes from this social matrix.

Collaboration then involves shared thinking, sharing expertise and ideas to create a new way of thinking to solve a problem. Collaborations can involve formal structures and processes or information actions. One thing that collaborations have in common is that the individuals recognize that they cannot solve a problem or create a new enterprise on their own. Rather, they come together around an idea or plan. Partners have equitable roles in decision-making as well as in the work that is to be accomplished. The focus of the partnership is on shared objectives and not just shared power. Conflicts are resolved through discussion and debate rather than authoritarian fiat. Well known collaborators such as Francis Crick and James D. Watson working on the human genome or Paul McCartney and John Lennon working on music were known for their willingness to engage in heated discussion in order to move a project forward (Schrage, 1990). In good collaborations, partners recognize the need for and respect the perspectives of others who add value to their work.

\section{Creating Successful Partnerships}

Successful business alliances or collaborations begin by understanding how to create effective, productive partnerships. In partnerships, two or more entities or people come together for mutual benefit. Often, organizations spend much of their 
time in assessing the financial terms of a partnership. While the financial aspect of partnerships is important, truly successful partnerships include an understanding of the need to manage the partnership in human terms (Cockerell, 2008).

Rosabeth Moss Kanter provides one of the seminal works in this area. In a 1994 Harvard Business Review article, Kanter outlines eight elements that are needed for partnerships to succeed (Kanter, 1994). She begins with individual excellence. Both partners bring value and strength to the alliance. They are not trying to mask weaknesses. Second, the partnership must be important to each person or entity and meet long term goals. There must be a solid business reason for the partnership. Third, partners recognize the interdependence of the relationship. If partners try to maintain their independence the partnership will not succeed. Fourth, everyone has to invest in the partnership by providing resources, expertise, or other tangible signs of commitment to the partnership. Fifth, the partners must be willing to share information to make the alliance work. Sixth, partners develop linkages so that they can operate smoothly together. Seventh, the alliance becomes a part of the formal structure of the two organizations and extends beyond the people who put the partnership together. And eighth, partners maintain their integrity and work in honorable ways to maintain trust. These eight characteristics form the foundation for successful alliances, partnerships, and collaborations.

Kanter goes on to describe the process of forming partnerships as a process similar to developing a romance or developing a relationship among two people. First partners need to select each other. Criteria for selection include knowing one's own strengths and one's industry, having rapport among top leaders of the companies, and having similar values. Shared vision at the top, reciprocal skills and competencies, and development of shared information sets are also part of the selection criteria.

Once a selection has been made, partners need to bring other stakeholders into the conversation to ensure balance in the alliance. Next, formal agreements are created to outline joint activities, to note how the relationships might expand, and to outline the agreed to interdependence between the partners. Think of this as a pre-nuptial agreement. Then, the hard work comes of learning each other's culture, noting similarities and differences in approaches, and learning how to resolve conflicts. Successful alliances and collaborations will develop mechanisms to bridge organizational and individual differences so that the partnership can flourish. Leaders stay engaged in the partnership to oversee strategic integration. Middle managers will come into the process to develop tactical integration which brings joint projects together. Operational integration will involve front line people and those carrying out the day to day work of the alliance. And interpersonal and cultural integration will help build the foundation for creating value, develop strong lines of communication, and helping everyone involved in the partnership or alliance to see the mutual benefit and shared creativity that comes from the 
partnership. For today's leaders, as Kanter notes, "intercompany relationships are a key business asset, and knowing how to nurture them is an essential managerial skill" (Kanter, 1994).

Another way to think about partnerships is not as a hierarchy of integration as Kanter proposes, but rather as neutral models that meet specific needs rather than normative perceptions of partnership. Joanna Smith and Priscilla Wohlstetter, in their research on public-private partnerships, developed four types of partnerships (Smith \& Wohlstetter, 2006). First, partnerships can be distinguished by the origin of the relationship among their partners. Some partnerships were formed as independent organizations bringing two groups together. Other partnerships were formed as spin-offs from independent organizations. Second, partnerships can be distinguished by the resources that are exchanged. Some partnerships are mostly financial efforts, some share human resources, others share space and physical resources and finally, some partnerships share organizational resources. A third category of partnerships involved the framework or structure of the partnership. Informal agreements might be developed from organizations or partners who had worked together previously and had a common task to complete. Other partnerships involve more formal agreements to outline how the partners will work together. A fourth category the authors identify is based on the depth of the relationship. Partnerships may involve only the top level of an organization or may become more integrated into both organizations involving more middle level managers and employees in the alliance or partnership. The authors conclude that any of these categories of partnerships can be successful and productive endeavors.

\section{Power of Partnerships-The Gallup Approach}

While the above models and descriptions of collaborations and partnerships provide a broad framework for creating and analyzing the impact of collaborations, Gallup Corporation has developed a more pragmatic approach identifying what participants can do to create powerful partnerships. The Gallup work on partnerships builds on the firm's work on positive organizational psychology, creating positive work environments as reported in First Break All the Rules, and identifying individual strengths reported in Now Discover Your Strengths (Buckingham \& Coffman, 1999; Buckingham \& Clifton, 2001). Using the same methodology of reviewing previous research and then analyzing thousands of interviews with participants throughout the world, Gallup has developed the Gallup Partnership Rating Scale which outlines 21 questions or items in 7 subscales that outline the factors that make for successful partnerships. The proprietary rating scale is included in the book the Power of 2: How to make the Most of Your Partnerships at Work and in Life (Wagner \& Muller, 2009). 
Gallup outlines seven key factors for successful partnerships. First, partners must have a common mission, common purpose, and common goals. They may have different reasons for pursuing the mission and need to understand how each person's motivation differs. Understanding the different perspectives on why each partner supports the common mission can help the partners build an understanding of how to maximize their strengths.

Perhaps one of the biggest challenges in creating partnerships is to ensure fairness. The workload needs to be divided fairly between partners with credit being shared among the partners. If one partner gets better rewards for the same work the partnership will not succeed. The need for fairness in the relationship is a primitive emotion that underlies all relationships. Work places that emphasize individual accomplishment over successful partnerships will find it more difficult to create the synergy needed for successful collaborations.

The next key factor is trust. There cannot be a true partnership without trust. Participants need to know they can count on each other to do what each says he or she will do. Partners acknowledge each other's contributions and tell others about how well they work together. In a variety of experiments on trust, researchers have shown that trust begets trust or "people return good for good and bad for bad, the world you inhabit is the world you make" (Wagner \& Muller, 2009, p. 95). If you are known as someone who collaborates, who can be trusted, and who is friendly, you will find trustworthiness. On the other hand if you choose to see interactions as competition, or if you prefer to play games to your own advantage, you will be seen as solitary, nasty, untrustworthy, and not a partner.

The fourth factor is acceptance. Partners recognize and build on each other's strengths rather than concentrating on weaknesses. They accept each other for who they are rather than trying to change each other. Partners accept that no one is perfect and that mistakes will be made. They need to understand each other's personalities and learn how to blend their different styles together to reach the common goals.

Forgiveness is also necessary for a successful partnership. Mistakes will be made, conflicts will develop, and trust may be violated. When this happens partners need to be able to forgive each other, reestablish trust, and rebuild a working relationship. Partners need to move beyond seeking revenge for wrongful acts, and work on ways to reestablish their working relationship. Interestingly, Gallup notes that venting your anger really does not work well. Venting only fuels one's anger and makes the situation worse rather than better. Instead, those who could find a middle ground between being aloof and being overwhelmed by the emotions of the situation were better able to work through the issues. They were able to analyze the situation, look for positive experiences in the situation and then learn how to incorporate these ideas into the working relationship (Wagner \& Muller, 2009, pp. 125-126). 
Next comes communication or as I call it "the Dreaded C Word." Good communication in a partnership can be summarized simply as good listening skills, rarely misunderstanding each other, and showing appreciation for what others do. One example of a partnership that was founded on their ability to communicate with each other is that of Francis Crick and James D. Watson working on decoding DNA. They were more successful than rival teams because they learned how to communicate with each other, to build off each other's ideas, to trust each other, and to share their expertise to solve problems.

The final element of successful partnerships is unselfishness. At some point in the building of a successful partnership, individual ego and selfcentered motives gives way to unselfishness. Partners take as much satisfaction in seeing others succeed as they do from their own successes. They know they will take risks for each other. Partners move from "What's in it for me" to "What's my partner getting out of this relationship." They move from "Are you doing enough" to "Am I doing enough as a partner." When partners reach this level of collaboration, they noted that these interactions were some of the best in their lives.

Gallup concludes that we are stronger and can be more successful when we move away from working alone to working with others to purse a shared mission with a partner or partners. Then we will be more successful. We can build on others strengths and expertise to create new ways to solve problems and to create success.

\section{Real World Examples}

Can partnerships succeed in the highly individualistic nature of higher education with faculty who value their autonomy and independence? How can we move beyond a culture that seems to be based on argumentative environments where criticism of ideas has turned into criticism of people to one that promotes collaboration and partnerships?

At the University of Nebraska-Lincoln (UNL), we are fortunate to have developed an administrative culture that promotes and rewards cross-college partnerships and collaborations. Our change process of creating a culture of collaboration began after the 2004 budget cuts where programs were eliminated and some tenured faculty lost their positions. The aftermath of the drastic, vertical cuts, included a series of conversations among the chancellor and the deans about how to come together and recreate the university in tough economic times. The deans increased their conversations about crosscollege initiatives. The campus emphasized interdisciplinary teams and the campus provided start up funding to help bring groups of faculty from different colleges together to work on projects. And in hiring new deans, the deans began to describe collaborative partnerships as a key. In fact, the deans told candidates for administrative positions, very bluntly, that if they preferred a competitive envi- 
ronment or "liked to swim with the sharks," they should not come to UNL. We now have a group of deans that collaborate rather than collide.

What has this change in attitude on the part of the upper administration done for the Libraries? How have we been able to capitalize on these environmental changes to create a thriving library? Let me give you two examples and the lessons we are learning from two different approaches. One is a twoyear partnership with the Department of Art and Art History on creating a digital image teaching collection to begin to replace the department's slide library for the art historians. The other example is the now ten-year partnership that created the Center for Digital Research in the Humanities, a true partnership with the College of Arts and Sciences. Both of these examples demonstrate how the Gallup factors are reflected in real experiences.

\section{Working with Art Historians}

In 2008, the new chair of the Department of Art and Art History (Art History Department) wanted to begin moving the department away from a traditional slide library to digital image collections. His dean referred him to the Dean of Libraries to talk about options available on campus to help begin this transition. The Libraries had created a robust digital image collection for the College of Architecture with over 100,00o images using the ContentDM system and were slowly eliminating the traditional architecture slide collections. The Libraries proposed that the Libraries partner with the Art History Department to use the same system for art history so that the various departments and colleges could more easily share digital images. We applied for an internal campus teaching grant to begin the process of digitizing the most heavily used slides to build a teaching tool for the faculty to help them transition from slides to the digital age. The project included two major challenges in developing the initial digital image databases. First was the challenge of helping the slide curator in the Art History Department understand that she would need to change her workflow and processes. We needed to teach her the differences between creating metadata in Dublin Core that could be easily searched, and running a database of information about the slides with no set vocabulary or cataloging scheme. Our second challenge was to design a projection system that could show true dual image projection in large classrooms, rather than split screen projection, and mimic the use of two slide carousels from one computer. The second challenge was more of a political than technical issue as the computing unit that runs general classrooms was not initially inclined to modify any of their systems or processes to allow for the needed changes. Overall, the project, which lasted two years, was successful in that we solved the initial common problems. The long term success of this transition is still uncertain as the 
funding for the initial project has ended. Using the Gallup outline we can analyze how this partnership worked for both parties and why the partnership became less robust after the grant ended.

\section{Gallup Analysis}

Common Mission. The project did have a common mission of creating a digital image library for the Department of Art and Art history. The Art History Department motivation was to move into the digital age as slide projectors disappear from the market. The Libraries' motivation was to create an image database that could be accessed and used in classes throughout the campus. While our motivations were different, our goals were compatible and fit well with the common mission.

Fairness. A number of planning meetings were held to outline work responsibilities and areas of expertise. Negotiations did need to occur throughout the first year to redesign work flow and work load as we became more experienced working with each other. We were careful to be sure that everyone was fairly recognized for their contributions to the project.

Trust. The Dean of Fine and Performing Arts and the Dean of Libraries have a long-standing collaborative working relationship. That relationship set the tone for creating trust among the members of the project including the Art History Department chair and the Architecture library visual images curator. Because we began from a spirit of good will, it was easier to establish and maintain trust throughout the project.

Acceptance. Acceptance was one of the major factors in this partnership as each of the stakeholders brought different expertise to the project. Art History faculty, although reluctant to move to digital images, were able to clearly assess for us what options were technically acceptable, explain how they teach large classes, and to describe their needs. The art slide curator was knowledgeable about the collection but not about technology. The Technology Support expert for the College understood both the faculty needs and classroom technology. The Libraries staff knew the cataloging and search engine capabilities. The Dean of Libraries was known as a campus negotiator and had access to top administrators when needed. By using people's strengths, the project group was able to pool expertise and move forward while accepting that no one expert was going to dominate the project.

Forgiveness. Fortunately, few true mistakes were made in this process and when they did occur they were corrected and the group moved on. The common mission kept the group focused on what was most important so that smaller, annoying but inconsequential issues could be resolved, become the subject of inside jokes, and not hold up the process.

Communication. As is true for so many joint partnerships, communication was 
a key factor. The project group met regularly. Conversations on work processes occurred daily. The Dean of Libraries and the Technical Support expert for the College worked closely together on the classroom issues, serving as a common front to affect change. Issues surfaced, decisions were made and most importantly documented, and the project moved on.

Unselfishness. This may be the weakest area of this partnership as the faculty who would be using the database were not interested in making major adjustments in their teaching but sought a system that would more easily transition them to the new age. While this is a reasonable request from the faculty perspective, it did limit some of the ideas that might have been tried. Since this was in essence a two year project, the lack of unselfish behavior did not impact the overall outcome.

Summary. As the Gallup outline demonstrates, many of the elements for a successful partnership were evident in the way the project was developed and implemented. The initial database was developed and is now over 200,00o images. Most of the Art History faculty are using the digital images in their classrooms. The newer faculty are very pleased to have digital technology available to them. Now that the grant is completed, it is up to the Art History department to find funds for staff to continue to digitize slides. The end of the funding ended the partnership and the project is now one that is coordinated rather than jointly planned and implemented. While the coordinated efforts include some Gallup elements such as common goals, the other elements are no longer a primary consideration for the project members. The Libraries remain a consultant to the slide curator when she has questions about cataloging and creating images. The classroom issues have been resolved. The Art History Department will continue to retrospectively digitize slides as time and funding permits. The database of digital images will continue to develop and the Department is positioned to provide digital services for the faculty.

\section{Center for Digital Research in the Humanities}

The real success story for UNL is the long term partnership that has developed into the Center for Digital Research in the Humanities. This center is a true, joint center that is co-directed by the College of Arts and Sciences and the Libraries. The Center belongs to both units, reports to both deans, and is funded by both Colleges. The Center has now brought in over \$7million in grants in 6 years, worked with over 60 faculty on projects, worked with over 140 students on digital humanities projects, and is an internationally known Center for cutting edge research. Gallup's model again helps us explain why this partnership has flourished and become a symbol on campus for how interdisciplinary, jointly run Centers can succeed. 
First some history of how the Center was started as it lays out some of the elements that led to the success of this partnership. In the mid-199os, the humanities faculty on campus decided to have a retreat to figure out how the humanities departments could get the attention of the Research Office which was focusing on how to expand grant activity mostly in the sciences. The Humanists were annoyed that they were being left out of the grant discussions. Their retreat, or battle planning event, resulted in an agreement among the humanities programs to identify a few core areas that they could leverage for funding. One of these areas was Text and Text Studies. At the same time, the Libraries had begun an electronic text center to experiment with creating digital texts for research purposes. The humanities librarians who also attended the retreat helped connect the electronic text center efforts with the Text and Text Studies group. The faculty in these areas cooperated on a few projects, and jointly explored changes in text studies as the humanities began to move into the digital age. By 200o, the College of Arts and Sciences was ready to hire a digital humanities faculty position using donor funds for a named position. With the help of the Libraries, the university recruited Dr. Kenneth Price who is the coordinator of the Walt Whitman Archive. He came to UNL to help develop a program in conjunction with the Libraries on digital humanities. Katherine Walter, who chairs digital initiatives and special collections in the Libraries, became Ken's partner in developing a proposal for a joint center. The Dean of Arts and Sciences and the Dean of Libraries then submitted the proposal to the University for funding through the Programs of Excellence competitive funding process. The Center received start up funding from the university to help implement the plan. The Libraries and the College both reallocated funding and positions to the Center with the College providing new faculty positions in this area. The libraries reassigned library faculty and staff positions to the program, and created a space in the libraries for the Center. In all, the deans provided over $\$ 600,000$ which was matched by the University in a multi-year, multi-million dollar grant. The Center was now born. The Center has grown from a few signature projects such as the Walt Whitman Archive and the Willa Cather archive to over 6o projects all based on faculty research interests. The Center library faculty have developed tools for analyzing digital texts, work in teams with the teaching faculty on creating digital scholarship, and provide training and workshops for those interested in this area. The College and Library faculty team teach courses in digital humanities, do joint presentations at international meetings, and help integrate the digital humanities efforts into the traditional academic departments and throughout the libraries. The group members no longer work as lone humanist researchers, but rather are changing the culture of the humanities to one of research done as cooperative ventures and partnerships. 


\section{Gallup Analysis}

Gallup analysis helps explain why this joint partnership with joint governance between campus units is successful.

Common Mission. From the beginning, the Center's initiators saw digital scholarship as thriving best when pursued collaboratively. The common mission of advancing digital humanities research was viewed as a core, up and coming program for the humanities departments and the University Libraries. All groups involved, scholars, librarians, administrators, and archivists, understood that getting people to talk across what were once dividing lines and are now porous borders was crucial. The goal of the Center is to be a place that fosters collaborative initiatives across disciplines and administrative units by bringing interested scholars together, providing them with support, expertise, leadership, and a congenial community of supportive colleagues. The Center collects and disseminates information on funding and other opportunities available to digital scholars. The Center serves as a friendly "home" for digital humanities scholarship.

Fairness. From the very beginning of establishing a digital humanities presence, the College and the Libraries have been willing to negotiate workload, resources, and support to ensure that all parties feel that they are being treated fairly. The Deans have stepped in when needed to ensure resources are available. Both Deans include the Center in overall strategic planning so that the Center is integrated into both units and is not seen as belonging more to one side or the other.

Trust. Trust has developed over time with the Center. Initially, formal governance documents were developed to outline responsibilities and decision-making processes. For example, it was decided that the Libraries would serve as the business unit for the Center and handle the administrative paperwork. Further, the Libraries are trusted by campus administration as one of the units that manages budgets very carefully and so the University Administration was supportive of this division of labor within the partnership.

Acceptance. Acceptance has grown over time as there is a fairly complex set of relationships within the Center. First, scholars were learning that they needed to work with highly skilled technology staff to complete digital projects. They slowly learned that the subject expertise and the technical viewpoints needed to merge if goals were to be reached. Some faculty believed that all scholars need to know how to do their own coding of text. Others prefer to concentrate on the analysis and rely on experts to code information. Computer programmers had to learn to "speak scholarly humanities" to figure out what the researchers needed and then translate that into computer work. The different technical groups had to learn to work together as well, learning new jargon, and beginning to understand different work styles. For some projects, the learning curve was fairly short and the mixed groups came together rather quickly. Other projects were not as smooth and work 
had to be redone as needs became clearer. We found that acceptance is a constant learning process, as new researchers work with the Center, as faculty develop new expertise and interests, and as the codirectors learn how to take advantage of each other's strengths and share the workload and decision-making responsibilities in the best ways possible.

Forgiveness. For the Center, forgiveness has become "not giving up" when projects go awry. Rather, we have developed a case study review process for projects that are not going well. For these reviews, we outline what is working, what is not working, and then adjust the systems to correct for problems. This may be done at the end of one grant cycle before the next grant cycle for the project begins. We then use the data from the case study in setting up the next project to try to avoid making similar mistakes. Problems are assumed to be issues of workflow and not to be taken personally. However, should it turn out that a personnel issue needs to be addressed, it is addressed and not left to fester.

Communication. For long standing partnerships, communication is crucial. Over time, communication systems can be taken for granted and then problems inevitably arise. For formal communication, the Center has an established a coordinating committee, does an annual retreat for goals setting and strategic planning, and each project team has a number of formal meetings. However, informal communication structures are needed as well. E-mails may be missed, people may feel they are being left out of important discussions, and misunderstandings occur. The Center staff try to keep on top of the communication issues but problems still arise. However, when a partnership has developed a solid foundation for working together, communication issues can and must be addressed before they develop into barriers to success.

Unselfishness. The Center faculty and staff are very supportive of each other and praise each other's successes. For example, the College of Arts and Sciences honored both co-directors as "College Stars" as part of the College of Arts and Sciences awards one year and did not just celebrate the faculty member from the College. Scholars regularly tell others about the support and expertise available through the Center. They talk about what they can do to make the project successful. Presentations at national meetings are often joint presentations among project members, each acknowledging the partnership approach and how that has strengthened their work. Of course, there are ego issues to address at times, but generally the success of the center is seen as the important common element that keeps the groups working together.

Summary. The Center for Digital Research in the Humanities at the UNL is a true interdisciplinary, jointly run partnership shared equally between two units. As the Gallup analysis shows, the Center is succeeding because it has addressed the key factors for successful partnerships. The Center's success can be seen in a number of quantitative and qualitative measures. On the quantitative side, as noted earlier, 
over 6o faculty scholarly projects have been done through the Center. Faculty would not be attracted to working with the Center if it did not have a reputation on campus for success. Students have worked on projects, both at the undergraduate and graduate level. Again, students would not be getting credit for Center work if the Center were not seen as a solid scholarly endeavor. From the University's administrative viewpoint, one of the key success factors is that the Center has leveraged over $\$ 7$ million in grants to support the work of digital humanities and is considered one of the most successful Programs of Excellence funded projects on campus. Qualitatively, the Center faculty and staff have learned how to create a true partnership approach. They have established systems for addressing the relationship issues of communication, acceptance, and trust that are so crucial in establishing close working relationships to meet mutual goals.

\section{Conclusion}

One way for Libraries to thrive in these turbulent economic times is to develop new forms of partnerships to advance the goals of the organization. While many organizations talk about collaborations and the need for different units to come together, the conversations are more about cooperative ventures than true collaborations. The cooperative efforts are important and have helped Libraries survive. The efforts working with other libraries and with vendors have provided economies of scale, allowed for cooperative purchasing agreements, and added efficiencies to local operations.

Now libraries have the opportunity and incentive to think more strategically about partnerships and collaborations. A core challenge, however, is that the culture of much of higher education is built on faculty independence, organizational silos, and a mixed set of values. Business operations seek efficiencies that may or may not fit well with a faculty who want to pursue their own work and have their own processes for getting the resources they need. Upper administrative units may want to establish controls for how people communicate externally. Units are working in good faith, but that faith is based on their own perspectives.

Libraries have a unique opportunity to begin to change how they interact with others in the higher education system because they are campus wide entities that work with both the business and academic sides of the institution. Libraries can take a leadership role in bringing together different groups to explore possible partnerships. Library leaders can bring together other upper campus administrators to explore opportunities for partnerships that go beyond traditional library services. For UNL, as noted, partnerships are developing around the creation of original scholarly content and around transforming content into digital form. While not a 
unique endeavor in higher education, the process for creating the working relationships that makes these projects successful is not a part of the traditional higher education culture.

The literature on establishing and maintaining partnership relationships provides library leaders with road maps they can use in creating new forms of partnerships. The processes for creating partnerships which can be effective on the campus can also guide libraries in establishing public private partnerships to advance the organizational mission. While discussion of public private partnerships is beyond the scope of this article, the relationship building elements are applicable. Libraries need to approach these new relationships cautiously and strategically to be sure that an equal partnership is really developing rather than a standard and often quite appropriate customer vendor relationship.

Developing new and exciting partnerships both with campus partners and entities within the library and higher education community provide libraries with new opportunities to refocus their programs so they can thrive. Well done strategic partnerships will benefit all parties involved in the relationship. Poorly done partnerships may devolve to cooperative efforts which fill a need but will not advance a common mission. As long as leaders remain vigilant to the relationship issues and truly assess the advantages of continuing to work together they will know when to continue in a partnership arrangement and when it is time to dissolve the partnership, get a divorce, and move on to the next opportunity.

\section{References}

Buckingham, M., and Clifton, D. O. (2001). Now Discover Your Strengths. New York: The Free Press.

Buckingham, M., and Coffman, C. (1999). First Break All the Rules: What the World's Greatest Managers Do Differently. New York: Simon and Schuster.

Cockerell, L. (2008). Creating Magic: 1o Common Sense Leadership Strategies from a Life at Disney. New York: Doubleday.

Davies, B., and Hentschke, G. (2006). Public-private partnerships in education: Insights from the field. School Leadership and Management, 26(3), 205-226.

Kanter, R. M. (1994). Collaborative advantage: The art of alliances. Harvard Business Review (July/August), 96-108.

Montiel-Overall, P. (2005). Toward a theory of collaboration for teachers and librarians. Online at http://www.ala.org/ala/mgrps/divs/aasl/aaslpubsandjournals/slmrb/slmrcontents/volume82005/theory.cfm 
Schrage, M. (1990). Shared Minds: The New Technologies of Collaboration. New York: Random House.

Smith, J., and Wohlstetter, P. (2006). Understanding the different faces of partnering: A typology of public-private partnerships. School Leadership and Management, 26(3), 249-268.

Wagner, R., and Muller, G. (2009). Power of 2: How to Make the Most of Your Partnerships at Work and in Life. New York, NY: Gallup. 